\title{
Antibiotic-Resistant Extended Spectrum B-Lactamase- and Plasmid-Mediated AmpC-Producing Enterobacteriaceae Isolated from Retail Food Products and the Pearl River in Guangzhou, China
}

\begin{abstract}
Qinghua Ye ${ }^{1,2,3}$, Qingping Wu ${ }^{1,2 *}$, Shuhong Zhang ${ }^{1,2}$, Jumei Zhang ${ }^{1,2}$, Guangzhu Yang ${ }^{1,2}$, Huixian Wang ${ }^{1,2}$, Jiahui Huang ${ }^{1,2}$, Mongtong Chen ${ }^{1,2}$, Liang Xue ${ }^{1,2}$ and Juan Wang ${ }^{1,2,4}$

' Guangdong Institute of Microbiology, State Key Laboratory of Applied Microbiology Southern China, Guangzhou, China, ${ }^{2}$ Guangdong Provincial Key Laboratory of Microbial Culture Collection and Application, Guangdong Open Laboratory of Applied Microbiology, Guangzhou, China, ${ }^{3}$ School of Bioscience and Bioengineering, South China University of Technology, Guangzhou, China, ${ }^{4}$ College of Food Science, South China Agricultural University, Guangzhou, China
\end{abstract}

OPEN ACCESS

Edited by:

Michael Gänzle,

University of Alberta, Canada

Reviewed by:

David Rodriguez-Lazaro,

University of Burgos, Spain

Byeonghwa Jeon,

University of Alberta, Canada

*Correspondence:

Qingping Wu

wuqp203@163.com

Specialty section

This article was submitted to

Food Microbiology,

a section of the journal

Frontiers in Microbiology

Received: 26 September 2016

Accepted: 13 January 2017

Published: 03 February 2017

Citation:

Ye Q, Wu Q, Zhang S, Zhang J, Yang $G$, Wang $H$, Huang J, Chen $M$,

Xue $L$ and Wang J (2017)

Antibiotic-Resistant Extended

Spectrum B-Lactamase- and

Plasmid-Mediated AmpC-Producing Enterobacteriaceae Isolated from

Retail Food Products and the Pearl

River in Guangzhou, China.

Front. Microbiol. 8:96.

doi: 10.3389/fmicb.2017.00096
We conducted a survey in 2015 to evaluate the presence of extended spectrum $\beta$-lactamase (ESBL)- and plasmid-mediated AmpC-producing Enterobacteriaceae in retail food and water of the Pearl River in Guangzhou, China, as well as their antibiotic resistance profiles. Samples (88 fresh food samples and 43 water samples) from eight different districts were analyzed by direct plating and after enrichment. Multidrug-resistant strains were found in 41.7 and $43.4 \%$ of food and water samples, respectively. ESBLs were found in 3.4 and $11.6 \%$ of food and water samples, respectively, and AmpC producers were found in 13.6 and $16.3 \%$ of food and water samples, respectively. Molecular characterization revealed the domination of bla $C T X-M$ genes; plasmidic AmpC was of the type DHA-1 both in food and water samples. Thirteen of Fifty one $\beta$-lactamase-producing positive isolates were detected to be transconjugants, which readily received the $\beta$-lactamase genes conferring resistance to $\beta$-lactam antibiotics as well as some non- $\beta$-lactam antibiotics. These findings provide evidence that retail food and the river water may be considered as reservoirs for the dissemination of $\beta$-lactam antibiotics, and these resistance genes could readily be transmitted to humans through the food chain and water.

\footnotetext{
Keywords: Enterobacteriaceae, antimicrobial resistance, ESBL, AmpC, $\beta$-lactamase, retail food, water of the pearl river, Guangzhou
}

\section{INTRODUCTION}

Enterobacteriaceae is a large family of gram negative, non-spore forming rods, which are facultative anaerobes and capable of fermenting sugars to various end products. The family Enterobacteriaceae consists of numerous genera of gram-negative bacilli, which include potential pathogens of several genera such as Escherichia, Enterobacter, Klebsiella, Proteus, Citrobacter, Serratia, Salmonella, Shigella, and Yersinia (Jarzab et al., 2011). These bacteria are transmitted via the fecal material and wastewater in different environments, including soil, water, food, and others (Bain et al., 2014). 
Antibiotic resistance is a major public health concern. Because of the wide use of broad-spectrum antibiotics, multidrug-resistant isolates have evolved, and increased in incidence through mutation, selection, and the spread of drug-resistant genes (World Health Organization, 2012). These drug-resistant bacteria can readily be transferred to humans through consumption of contaminated water and food, contributing to the spread and perseverance of antibioticresistant bacteria in the general population and environment (Calbo et al., 2011; Leverstein-van Hall et al., 2011; Overdevest et al., 2011). The production of $\beta$-lactamase is the primary mechanism of antibiotic resistance in Enterobacteriaceae, and the extended spectrum $\beta$-lactamase (ESBL)- and plasmid-mediated cephalosporinase (AmpC)-producing isolates constitute a particularly important branch in this lineage (Bush and Jacoby, 2010; Nordmann et al., 2011). Since the 2000s, ESBL- and AmpC-producing isolates have been reported worldwide. ESBL and AmpC producers have not only been isolated from hospital settings but are also disseminated in other environments such as rivers and foods, domestic, and wild animals, healthy humans, wastewater, and other sources (Ben Sallem et al., 2012; Blaak et al., 2014; Durso and Cook, 2014).

ESBLs have the ability to hydrolyze penicillins, first-, second-, and third-generation cephalosporins, and aztreonam, but not cephamycins and carbapenems, and are usually inhibited by the so-called "classical" $\beta$-lactamase inhibitors such as clavulanic acid, tazobactam, and sulbactam, respectively (Lee et al., 2012). Most ESBLs can also confer resistance to fourth-generation cephalosporins (such as cefepime [FEP] or cefpirome) (Bush and Jacoby, 2010). ESBLs include the classical extended-spectrum TEM-, SHV-, and OXA-type enzymes, which have evolved from their parent enzymes (TEM-1, 2, 13; SHV-1; and OXA$1,2,10)$, and also include newer enzymes with a similar spectrum of hydrolytic activity but a different evolutionary history, such as the CTX-M-type enzymes (Livermore, 2008; Pfeiier et al., 2010). SHV- and TEM-type ESBLs were the main cause of third-generation cephalosporin resistance among the Enterobacteriaceae in the 1980s (Pitout, 2012). In the early 2000s, the CTX-M-type ESBLs rose to dominance over the TEM- and SHV-type enzymes (Canton et al., 2012; Peirano et al., 2012). Plasmid-mediated AmpC $\beta$-lactamase was first reported in the 1980s (Philippon et al., 2002), which confers bacteria with resistance to a broad spectrum of $\beta$-lactams, including penicillins, oxyimino- $\beta$-cephalosporins, cephamycins, and (variably) aztreonam (Singhal et al., 2005), but not FEP, cefpirome, and carbapenems; AmpC $\beta$-lactamase producers are usually not inhibited by the "classical" $\beta$-lactamase inhibitors mentioned above, but are inhibited by boronic acid and cloxacillin (Pitout et al., 2010). Plasmid-mediated AmpC $\beta$-lactamases include MOX-, CIT-, DHA-, ACC-, FOX-, and EBC-type enzymes, and CMY-2 of CIT-type enzymes has shown the broadest geographic spread and is one of the main causes of $\beta$-lactam resistance at present (Whichard et al., 2005; Egorova et al., 2008).

As the freshwater source to agricultural environments for Guangzhou and surrounding towns, the water of Pearl River has been influenced by non-point and point pollution along with the rapid industrial, agriculture, and municipal development in this region; consequently, the inputs of antibiotics and other contaminants into the river have rapidly increased (Yang et al., 2010, 2011; Li et al., 2011). Previous studies have focused on investigating ESBL and AmpC in clinical settings (Gharout-Sait et al., 2015; Leistner et al., 2015; Nielsen et al., 2015; Soha and Lamiaa, 2015), but few studies have been conducted on the dissemination of ESBL and AmpC in food and agricultural environments (Blaak et al., 2014; Reuland et al., 2014; Veldman et al., 2014). Some reported have described ESBL-producing isolates in chicken, pork, beef, other raw meats (Kant and Mevius, 2013; Ojer-Usoz et al., 2013; Reich et al., 2013; Casella et al., 2015), fresh vegetables (Yuan et al., 2009; Reuland et al., 2014), and even raw milk (Thaker et al., 2012; Abate et al., 2016), Ready-to-eat street-vended food (Campos et al., 2015), but fewer reports have described other types of foods. Moreover, there are limited studies on the presence of antibiotic-resistant Enterobacteriaceae isolates in the aquatic environment and food samples of China (Yuan et al., 2009; Tao et al., 2010), and none of these have focused on the Guangzhou region. Detection of ESBLs and plasmid-mediated AmpC lactamases is necessary for effective surveillance and epidemiology, as well as to develop appropriate infection control strategies associated with resistance mechanisms. Toward this end, the aim of this study was to contribute new knowledge on the diversity of Enterobacteriaceae from retail food and water of Pearl River in Guangzhou, characterize their resistance to antibiotics, and determine the presence of ESBL- and AmpC-producers in the recovered isolates.

\section{MATERIALS AND METHODS}

\section{Sample Collection}

During the period from October 2014 to January 2015, a total of 88 fresh foods samples which were composed of raw meat products, aquatic products (including freshwater aquatic product and marine food product), raw vegetables, retail-level ready-toeat (RTE) food (including cooked meat and roast meat), frozen food (including frozen meat products), and mushrooms, were obtained from eight large supermarkets, and 43 water samples were collected from 16 selected sites of Pearl River in Guangzhou. The sampling sites were distributed throughout eight different districts in Guangzhou: Huadou, Yuexiu, Liwan, Haizhu, Tianhe, Conghua, Panyu, and Nansha. Water samples $(225 \mathrm{~mL})$ were collected in sterile bottles at a depth of $50 \mathrm{~cm}$ below the water surface in the middle of the river. All samples were maintained below $4^{\circ} \mathrm{C}$ during transportation, and testing was initiated within $2 \mathrm{~h}$ after receipt.

\section{Isolation and Identification of Enterobacteriaceae}

In brief, $25 \mathrm{~g}$ or $225 \mathrm{~mL}$ of the respective food or water sample was homogenized in $25 \mathrm{~mL}$ Enterobacteria enrichment broth (Huankai, Guangzhou, China) for $30 \mathrm{~s}$ in stomacher bags (Huankai, Guangzhou, China). Homogenates were incubated at $37^{\circ} \mathrm{C}$ for $24 \mathrm{~h}$; thereafter, a loopful of the enrichment broth culture was streaked onto violet red bile glucose agar 
selective medium (Huankai, Guangzhou, China), and the typical colonies that formed on the selective agar were streaked onto tryptic soy agar (Huankai, Guangzhou, China). Phenotypic characteristics, Gram staining, oxidase, and fermentation tests were performed for the isolated bacterial colonies to screen for the presence of enterobacteria. Gram-negative, oxidasenegative, and fermentation-positive isolates were biochemically identified with API 20E (BioMe'rieux, Marcy I'Etoile, France). Subsequently, the isolates were identified using 16S rRNA gene sequencing in cases in which the API result was not discriminatory. The $16 \mathrm{~S}$ rRNA gene was amplified under standard polymerase chain reaction (PCR) conditions using the primers 27f (5'-GAGTTTGATYMTGGCTCAG-3') and 1492r (5'-TACGGYTACCTTGTTACGACT- $3^{\prime}$ ) and sequenced (Lane, 1991).

\section{Antimicrobial Susceptibility Testing}

The strains were tested for susceptibility to antimicrobial susceptibility using the disk diffusion technique following the protocols of the Clinical and Laboratory Standards Institute Clinical Laboratory Standards Institute (2011). The following $16 \mathrm{AM}$ agents were tested: ampicillin (AMP, $30 \mu \mathrm{g}$ ), amoxicillin/clavulanic (AMC, 20/10 $\mu \mathrm{g}$ ), aztreonam (AZM, 30 $\mu \mathrm{g}$ ), imipinem (IPM, $10 \mu \mathrm{g})$, meropenem (MEM, $10 \mu \mathrm{g})$, FEP $(30 \mu \mathrm{g})$, gentamicin $(\mathrm{CN}, 10 \mu \mathrm{g})$, tobramycin (TM, $10 \mu \mathrm{g})$, tetracycline (TE, $30 \mu \mathrm{g}$ ), ciprofloxacin (CIP, $5 \mu \mathrm{g}$ ), levofloxacin (LEV, $5 \mu \mathrm{g}$ ), trimethoprim/sulfamethoxazole (SXT, 1.25/23.75 $\mu \mathrm{g}$ ), chloramphenicol (C, $30 \mu \mathrm{g})$, cefotaxime (CTX, $30 \mu \mathrm{g}$ ), ceftazidime (CAZ, $30 \mu \mathrm{g}$ ), and cefoxitin (FOX, $30 \mu \mathrm{g}$ ) (all from Oxoid Ltd., Basingstoke, UK). Staphylococcus aureus ATCC 25923 and Escherichia coli ATCC 25922 were used as quality control strains for this study. Zones of inhibition were measured with a precision caliper to the nearest $0.01 \mathrm{~mm}$. Isolates exhibiting resistance to at least three antimicrobial agents tested were considered as multidrug-resistant strains.

\section{Phenotypic ESBL/AmpC Testing}

All enterobacterial isolates were screened for ESBL production by the double-disk synergy test (DDST) using CTX and CAZ with and without clavulanic acid (BD, Franklin Lakes, UN), according to the Clinical Laboratory Standards Institute (2011). Furthermore, a FOX disk (Oxoid, Basingstoke, UK) was added to this test to detect AmpC phenotypes (Stalder et al., 2014). All isolates classified as intermediate or resistant to FOX using CLSI criteria $(\leq 17 \mathrm{~mm}$ ) were suspected to be AmpC-positive. A confirmation test for AmpC was performed using the threedimensional extract method (TDEM) according to Coudron et al. (2000) with minor modifications. In brief, $50 \mu \mathrm{L}$ of a $0.5 \mathrm{McF}$ arland bacterial suspension prepared from an overnight tryptic soy agar (Huankai, Guangzhou, China) was inoculated into $10 \mathrm{ml}$ of tryptic soy broth (Huankai, Guangzhou, China) and the culture was grown for $4 \mathrm{~h}$ at $37^{\circ} \mathrm{C}$. The cells were concentrated by centrifugation, and crude enzyme preparations were made by freezing-thawing the cell pellets five times. The surface of a Mueller-Hinton agar plate (Huankai, Guangzhou, China) was inoculated with E. coli ATCC 25922; a $30 \mu \mathrm{g}$ cefoxitin disk was placed on the inoculated agar. With a sterile scalpel blade, a slit beginning $5 \mathrm{~mm}$ from the edge of the disk was cut in the agar in an outward radial direction. By using a pipet, 25-30 $\mu \mathrm{L}$ of enzyme preparation was dispensed into the slit, beginning near the disk and moving outward. Slit overfill was avoided. The inoculated media were incubated overnight at $37^{\circ} \mathrm{C}$. Enhanced growth of the surface organism at the point where the slit intersected the zone of inhibition was considered a positive three-dimensional test result and was interpreted as evidence for the presence of AmpC beta-lactamase. All isolates displaying ESBL or AmpC were further characterized in more detail by resistance gene identification.

\section{Characterization of $\beta$-Lactamase Genes}

The genes encoding TEM, SHV, OXA, and CTX-M enzymes for ESBL, and MOX, CIT, DHA, ACC, EBC, and FOX enzymes for AmpC $\beta$-lactamases were analyzed by PCR and sequencing in all ESBL-positive and AmpC-positive isolates. Nucleotides and their deduced amino acid sequences were compared with those included in the GenBank database to confirm the specific type of $\beta$-lactamase gene. The primer sequences and their positions, PCR conditions, and references are summarized in Table S1.

\section{Detection of Integrons}

The presence of intI1 and intI2 genes (encoding class 1 and class 2 integrases, respectively) was examined by PCR (Table S1).

\section{Conjugation Transfer Experiments}

Conjugation experiments were performed with the plasmid-free recipient strain Escherichia coli DH5 $\alpha$ (Kallova et al., 1995). In brief, single colonies of the donor and recipient were inoculated in Luria-Bertani broth (Huankai, Guangzhou, China) and grown overnight at $37^{\circ} \mathrm{C}$. Subsequently, equal volumes of the donor and recipient cultures were mixed and incubated overnight at $37^{\circ} \mathrm{C}$ without shaking. Serial dilutions were then plated on Luria-Bertani agar selection plates supplemented with 50 $\mu \mathrm{g} / \mathrm{mL}$ ampicillin (National institutes for food and drug control, Beijing, China). Experiments were run in parallel including the donor strain alone and acceptor strain alone as controls for all transconjugation experiments to ensure the effectiveness of the selective plates used. Transconjugants growing on the selection plates were subjected to DDST, TDEM, and PCR to confirm the presence of the ESBL/AmpC phenotype.

\section{RESULTS}

\section{Identification of Enterobacteriaceae Isolates}

A total of 343 suspicious gram-negative bacterial isolates (248 isolates from food samples and 95 isolates from water samples) were selected from the plates and subjected to biochemical identification. Of these, $282(82.2 \%)$ isolates were confirmed as members of the Enterobacteriaceae family, of which 206 (83.1\%) and $95(80 \%)$ strains isolated from food and water, respectively. Among the isolates from retail food, the most abundant genera were Citrobacter (17.5\% of the isolates belonged to $C$. freundii, $C$. braakii, C. amalonaticus, C. youngae, and C. farmeri), Klebsiella 
TABLE 1 | Percentage of isolated Enterobacteriaceae strains from retail food and water in Guangzhou.

\begin{tabular}{|c|c|c|c|c|c|}
\hline Species & Isolats from food & Isolates from water & Species & Isolats from food & Isolates from water \\
\hline C. freundii & 28 (13.6) & $14(18.4)$ & Moellerella wisconsensis & $4(1.9)$ & $0(0)$ \\
\hline C. farmeri & $1(0.5)$ & $0(0)$ & E. intermedius & $2(1)$ & $0(0)$ \\
\hline C. brakii & $4(1.9)$ & $0(0)$ & E. asburiae & $1(0.5)$ & $0(0)$ \\
\hline C. yourgae & $1(0.5)$ & $0(0)$ & E.cloacae & $17(8.3)$ & $10(13.2)$ \\
\hline C. amalonaticus & $2(1.0)$ & $0(0)$ & E. earogens & $5(2.4)$ & $2(2.6)$ \\
\hline S. fonticola & $0(0)$ & $3(3.9)$ & E. cancerogenus & $3(1.4)$ & $0(0)$ \\
\hline S. liquefaciens & $1(0.5)$ & $0(0)$ & E. cayogenus & $1(0.5)$ & $0(0)$ \\
\hline S. marsenscens & $9(4.4)$ & $1(1.3)$ & K. oxoytoca & $12(5.8)$ & $4(5.3)$ \\
\hline Kluyvera spp. & $6(2.9)$ & $4(5.3)$ & K. terrigena & $4(1.4)$ & $1(1.3)$ \\
\hline Pantoea spp. & $6(2.9)$ & $1(1.3)$ & K. pneumoniae & $16(7.8)$ & $18(23.7)$ \\
\hline Hafnia alvei & $9(4.4)$ & $0(0)$ & P. vulgaris & 7 (3.4) & $2(2.6)$ \\
\hline Edwardsiella tarda & $2(1.0)$ & $0(0)$ & P. mirabillis & $1(0.5)$ & $0(0)$ \\
\hline Rahnella aquatilis & $1(0.5)$ & $0(0)$ & Morganella.Morganii & $31(15.0)$ & $2(2.6)$ \\
\hline Cedecea spp & $6(2.9)$ & $0(0)$ & Salmonella spp & $2(1.0)$ & $0(0)$ \\
\hline Ewingella americana & $1(0.5)$ & $0(0)$ & E.coli & 17 (8.3) & $18(23.7)$ \\
\hline Buttiauxella agrestis & $1(05)$ & $0(0)$ & Total & $206(100)$ & 76 (100) \\
\hline Provideneia spp & $6(2.9)$ & $1(1.3)$ & & & \\
\hline
\end{tabular}

(15.0\% of the isolates belonged to K. pneumoniae, K. oxytoca, and $K$. terrigena), Morganella (15.0\% of the isolates belonged to Morganella morganii) and Enterobacter (14.1\% of the isolates belonged to E. cloacae, E. aerogenes, E. amnigenus, E. intermedius, E. asburiae, and E. cayogenus). Species affiliation analysis revealed that the most common taxa were Morganella morganii (15.0\%), followed by C. freundii (13.6\%), E. coli (8.3\%), E. cloacae (8.3\%), and K. pneumoniae (7.8\%). The remaining isolates belonged to Serratia spp., Hafnia alvei, Kluyvera spp., Proteus spp., Pantoea spp., Providencia spp., Cedecea spp., Moellerella wisconsensis, Edwardsiella tarda, Salmonella spp., Rahnella aquatilis, Ewingella americana, and Buttiauxella agrestis (Table 1). While among the isolates from water, the most common taxa were E. coli (23.7\%), followed by C. freundii (18.4\%), K. pneumoniae (17.1\%), and E. cloacae (15.8\%). The remaining isolates belonged to $K$. oxytoca, K. terrigena, E. aerogenes, Kluyvera spp., S. marcescens, S. fonticola, P. vulgaris, Pantoea spp., Morganella morganii, and Providencia rettgeri (Table 1).

\section{Antibiotic Resistance Patterns}

The results of the susceptibility testing of the 282 Enterobacteriaceae isolates from food and water against 16 antimicrobial agents are presented in Figure 1. Resistance was observed for all antibiotics tested in this study, and the highest prevalence recorded was against AMP (62.6\% in retail food and $75.0 \%$ in water). A high percentage of the isolates were resistant to other $\beta$-lactam antibiotics tested, such as AMC $(46.1 \%$ in retail food and $44.7 \%$ in water) and FOX (31.6\% in retail food and $36.8 \%$ in water), but not CAZ $(4.9 \%$ in retail food and $7.9 \%$ in water) and FEP (7.8\% in retail food and $5.3 \%$ in water). Moreover, high levels of resistance to TE (36.4\% in retail food and $31.6 \%$ in water), C (20.9\% in retail food and $27.3 \%$ in water), and SXT (20.4\% in retail food and $27.6 \%$ in water) were also observed, and the resistance rate to aminoglycoside, quinolones

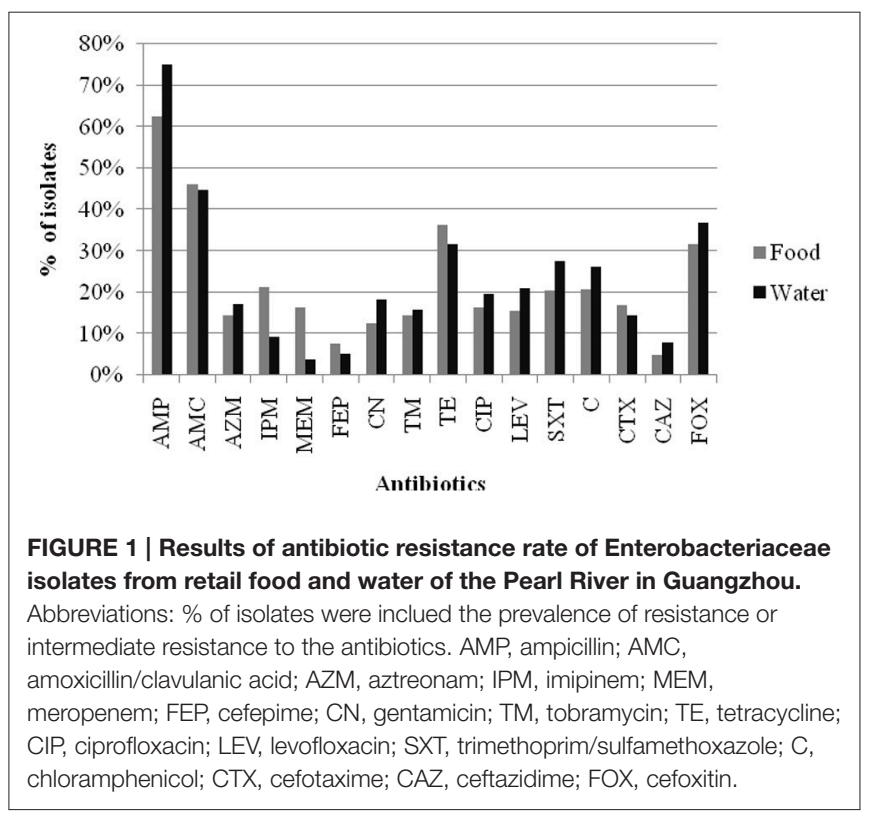

antibiotics varied from 12.6 to $21.1 \%$ in retail food and water, respectively. However, approximately 15 and 5\% of the strains showed moderate resistance to carbapenems antibiotics in retail food and water, respectively. Approximately 25.2\% (71/282) of the isolates were sensitive to all antimicrobials, comprising $28.6 \%$ $(59 / 206)$ and $15.8 \%(12 / 76)$ of those isolated from retail food and water, respectively. In addition, $42.2 \%(119 / 282)$ of the strains exhibited multidrug resistance phenotypes, demonstrating resistance to antibiotics from at least three different classes, including $41.7 \%(86 / 206)$ and $43.4 \%(33 / 76)$ of the strains isolated from retail food and water, respectively (Figure 2). 


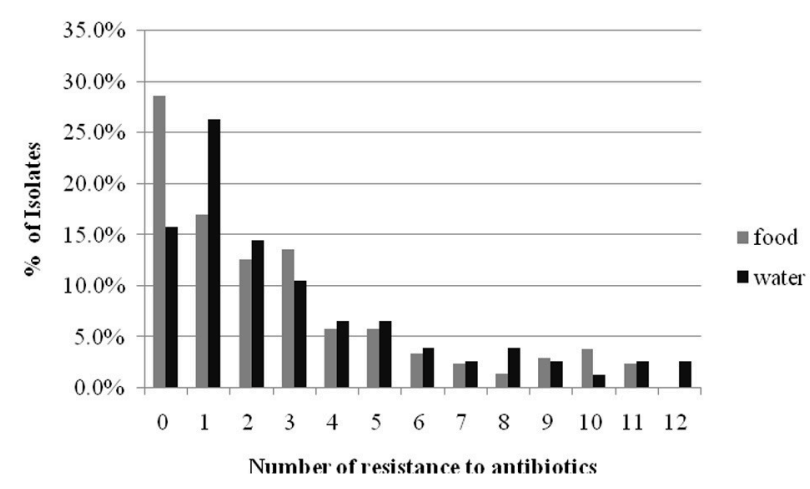

FIGURE 2 | The comparison of mult-drug resistance rates of Enterobacteriaceae isolated from retail food and water of the Pearl River in Guangzhou.

\section{Detection of ESBL and AmpC Production and Characterization of Related Genes}

A total of $53(18.8 \%)$ isolates that showed reduced susceptibility to CTX and/or CAZ by the disk diffusion method were tested for ESBL production. Based on the results, 25 (8.9\%) of the isolates were designated as ESBL producers by the DDST, of which $15(7.3 \%)$ and $10(13.2 \%)$ strains isolated from retail food and water, respectively. Genes encoding $\beta$-lactamase were detected in these 15 isolates from retail food, mainly in $E$. coli $(n=4), M$. morganii $(n=3)$. The most frequently detected genes were blasHV $(n=9)$, followed by bla $(n=4)$, bla $a_{O X A}(n=2)$, and bla $a_{C T X-M}(n=2)$. All bla $a_{S H V}$ and $b a_{T E M}$ sequences were found to encode the broad-spectrum $\beta$-lactamases SHV- 1 and TEM-1, respectively. SHV-1 was the most dominant genotype $(n=9)$ and was identified in two E. coli isolates, and in single isolates of Serratia liquefaciens, C. amalonaticus, K. oxytoca, Cedecea neteri, M. morganii, and E. cloacae. One isolates carried the bla $a_{S H-1}$ gene in association with bla $a_{X A-1}$ (C. frendii). Four isolates (two M. morganii, one each of E. coli and $H$. alvei) carried only $b a_{T E M-1}$. One $E$. coli isolate harbored only the bla $a_{C T X-M-55}$ gene, whereas in a P. mirabilis isolate, bla OXA-1 was associated with bla (Table 2). And genes encoding $\beta$-lactamase were detected in these 10 isolates from water, mainly in E. coli $(n=5), C$. frendii $(n=$ $2)$, and $K$. pneumoniae $(n=2)$. The most frequently detected genes were bla $a_{S H V}(n=6)$, followed by $\operatorname{bla}_{T E M}(n=5)$ and $b a_{C T X-M}(n=5)$. All bla $a_{S H V}$ and bla $a_{T E M}$ sequences were found to encode the broad-spectrum $\beta$-lactamases SHV- 1 and TEM1 , respectively. SHV-1 was identified in single isolates of $E$. coli and C. frendii. Three isolates carried the bla $a_{S H-1}$ genein association with $b l a_{C T X-M}$ (two E. coli and one K. pneumoniae). One $K$. pneumoniae isolates carried only $b_{T E M-1}$, whereas in other isolates, bla $a_{C T X-M-14}$ (one Providencia rettgeri) and bla $a_{C M Y-2}$ (one E. coli and one C. freundii) was associated with bla $_{T E M-1}$. One E. coli isolate simultaneously harbored the bla $a_{S H V-1}, b l a_{T E M-1}$, and $b l a_{C T X-M-65}$ genes (Table 3).

A total of $94(32.9 \%)$ isolates that showed reduced susceptibility to FOX were tested for a putative AmpC phenotype.
Twenty-eight (9.9\%) of the isolates were designated as AmpC producers according to the TDEM, of which 19 (9.2\%) and 9 (11.8\%) strains isolated from retail food and water, respectively. All 27 AmpC-positive isolates harbored genes encoding AmpCs. Nineteen isolates from retail food were mainly detected in $M$. morganii $(n=6), C$. freundii $(n=5)$, and $K$. pneumoniae $(n=$ 2) (Table 2). The most frequently detected genes were $b l a_{D H A}(n$ $=13)$ followed by $b l a_{C I T}(n=4)$, and $b l a_{A C C}(n=3)$, but bla $a_{M O X}$, $b l a_{E B C}$, and $b l a_{F O X}$ were not detected. In all cases, $b l a_{D H A}$, $b l a_{C I T}$, and $b l a_{A C C}$ encoded the AmpC $\beta$-lactamases DHA-1, CMY-2, and ACC-1, respectively. Except for one K. Oxytoca that simultaneously harbored the $b l a_{C M Y-2}$ and $b l a_{D H A-1}$ genes, the others harbored only single AmpC $\beta$-lactamase genes (Table 4). Nine isolates from water were mainly detected in C. freundii ( $n$ $=3)$, E. cloacae $(n=3)$, and E. coli $(n=2)$. The most frequently detected genes were bla $a_{D H A}(n=6)$ followed by bla $a_{C I T}(n=3)$, but $b l a_{A C C}, b l a_{M O X}, b l a_{E B C}$, and $b l a_{F O X}$ were not detected. In all cases, bla $a_{D H A}$ and bla $a_{C I T}$ encoded the AmpC $\beta$-lactamases DHA1, CMY-2, respectively. Except for one K. oxytoca and one E. coli isolate that simultaneously harbored the bla $a_{C M Y-2}$ and $b l a_{T E M-1}$ genes, the others harbored only single AmpC $\beta$-lactamase genes (Table 3).

Overall, $6.1(8 / 131)$ and $14.5 \%$ (19/131) of all samples contained ESBL- and AmpC-producing Enterobacteriaceae, respectively. Further subdivision into Enterobacteriaceae species isolated from food and water showed that $11.6(5 / 43)$ and $16.3 \%(7 / 43)$ of the water samples tested, and $3.4(3 / 88)$ and $13.6 \%(12 / 88)$ of the retail food samples tested contained ESBL-producing and AmpC-producing Enterobacteriaceae, respectively (Table 4). Among the retail food samples, ESBLproducing Enterobacteriaceae were detected on one of frozen foods, raw meat products, and raw vegetables respectively, and AmpC-producing Enterobacteriaceae were detected on six of aquatic products, two of frozen foods, two of raw meat products, and two of RTE foods, respectively, with none detected on the mushrooms and vegetables.

By antibiotic resistance patterns, our study detected a higher resistance rate in $\beta$-lactamase-producing positive strains than negative strains (Figure 3).

\section{Detection of Integrons}

Class 1 integrons were present in all of the 51 ESBL-(by DDST) and AmpC-producing strains, but class 2 integrons were not identified in this collection (Tables 2, 3).

\section{Conjugal Transfer of ESBL- and AmpC-Encoding Genes}

In the conjugation experiments, transfer of the ESBL and AmpC phenotype was demonstrated in 9 of the 25 ESBL (by DDST) strains tested ( 5 isolates from food samples and 4 isolates from water samples), and in 5 of $28 \mathrm{AmpC}$ strains tested (3 isolates from food samples and 2 isolates from water samples); however, transconjugants could not be recovered in the other strains. All of the obtained transconjugants received the $\beta$-lactamase genes and acquired the ESBL and AmpC phenotypes. In addition, four transconjugants (single E. coli and K. pneumoniae isolates, and two C. freundii isolates) acquired the ESBL and AmpC 
TABLE 2 | Results of $\beta$-lactamase gene types, integrons and transconjugants of $\beta$-lactamase -producing Enterobacteriaceae from retail food in Guangzhou.

\begin{tabular}{|c|c|c|c|c|c|c|}
\hline No. & Strains & Resources & Species & $\beta$-lactamase phenotypes & Integrons & Transconjugants $^{a}$ \\
\hline 1 & $3-3$ & Raw meat products & S. liquefaciens & SHV-1 & Intl & - \\
\hline 2 & $4-2$ & Raw meat products & E. coli & SHV-1 & Intl & + \\
\hline 3 & $19-1$ & Frozen food & E. coli & SHV-1 & Intl & - \\
\hline 4 & $19-4$ & Frozen food & E. coli & CTX-M-55 & Intl & + \\
\hline 5 & $29-2$ & Raw vegetables & C. frendii & SHV-1+OXA-1 & Intl & + \\
\hline 6 & $34-3$ & Mushroom & C. amalonaticus & SHV-1 & Intl & - \\
\hline 7 & $44-2$ & RTE food & K. oxytoca & SHV-1 & Intl & - \\
\hline 8 & $64-1$ & Raw meat products & E. coli & TEM-1 & Intl & - \\
\hline 9 & $51-2$ & Mushroom & Cedeca neteric & SHV-1 & Intl & - \\
\hline 10 & 68B-2 & Aquatic products & Morganella morganii & SHV-1 & Intl & - \\
\hline 11 & $69-4$ & Aquatic products & Morganella morganii & TEM-1 & Intl & - \\
\hline 12 & $80-3$ & Aquatic products & Hafnia alvei & TEM-1 & Intl & + \\
\hline 13 & $83-2$ & Raw meat products & E. cloacae & SHV-1 & Intl & + \\
\hline 14 & $84-4$ & Raw meat products & P. mirabilis & CTX-M-65+OXA-1 & Intl & - \\
\hline 15 & $88 \mathrm{~A}-2$ & Aquatic products & Morganella morganii & TEM-1 & Intl & - \\
\hline 16 & $1-4$ & Raw meat products & C. freundii & CMY-2 & Intl & - \\
\hline 17 & $10 \mathrm{~A}-4$ & Aquatic products & Morganella morganii & DHA-1 & Intl & + \\
\hline 18 & 10B-1 & Aquatic products & Morganella morganii & DHA-1 & Intl & - \\
\hline 19 & $13 \mathrm{~A}-2$ & Aquatic products & Morganella morganii & $\mathrm{DHA}-1$ & Intl & - \\
\hline 20 & 13B-1 & Aquatic products & Morganella morganii & CMY-2 & Intl & - \\
\hline 21 & $15-4$ & Aquatic products & E. asburiae & DHA-1 & Intl & - \\
\hline 22 & 15B-3 & Aquatic products & Morganella morganii & CMY-2 & Intl & - \\
\hline 23 & $17-3$ & Frozen food & C. freundii & DHA-1 & Intl & - \\
\hline 24 & $45-2$ & RTE food & K. oxytoca & CMY-2+DHA-1 & Intl & + \\
\hline 25 & $72-2$ & Raw meat products & Pantoea spp & ACC-1 & Intl & - \\
\hline 26 & $73-2$ & Aquatic products & C. freundii & DHA-1 & Intl & - \\
\hline 27 & $81-1$ & Raw meat products & K. pneumoniae & DHA-1 & Intl & + \\
\hline 28 & $81-2$ & Raw meat products & K. pneumoniae & $\mathrm{DHA}-1$ & Intl & - \\
\hline 29 & $86 \mathrm{~A}-2$ & Aquatic products & Morganella morganii & DHA-1 & Intl & - \\
\hline 30 & $86-2$ & Aquatic products & C. freundii & DHA-1 & Intl & - \\
\hline 31 & $86-3$ & Aquatic products & C. freundii & $\mathrm{DHA}-1$ & Intl & - \\
\hline 32 & $89-2$ & Frozen food & E. cloacae & DHA-1 & Intl & - \\
\hline 33 & $90-1$ & RTE food & Kluyvera spp & ACC-1 & Intl & - \\
\hline 34 & $96-1$ & Aquatic products & Salmonella spp & ACC-1 & Intl & - \\
\hline
\end{tabular}

a, +, have been obtained transconjugants; -, have not been obtained transconjugants.

phenotypes as well as resistance to SXT, TM, TE, and CN, respectively (Table 5).

\section{DISCUSSION}

With the wide use of antibiotics, high levels of antibiotic compounds and antibiotic resistance have been detected in all kinds of environments such as soils, food, water, sediments, and sludge (Knapp et al., 2011; Ben Sallem et al., 2012; Thevenon et al., 2012; Blaak et al., 2014; Durso and Cook, 2014). Therefore, the prevalence of antibioticresistant bacteria has become a significant environmental and health challenge. Enterobacteriaceae have been considered to play a major role in the ongoing mobilization of resistance genes from environmental microbes to other species, with eventual transmission to human pathogens, and vice versa (Machado et al., 2009; Tacão et al., 2012). This trend has been mainly addressed through epidemiological studies of the spread of ESBLs in aquatic environments and foodproducing animals (Machado et al., 2009; Lu et al., 2010; Tacão et al., 2012). Nevertheless, genes encoding clinically important ESBLs in Enterobacteriaceae besides those in foodproducing animals and in the water from Pearl River have not been performed in Guangzhou. Thus, the present study focused on the antibiotic resistance patterns, and identified the ESBL and AmpC producers in retail food and in Pearl River, which is the primary freshwater source for Guangzhou city.

Analysis of the antibiotic susceptibility profile revealed that a very high percentage (43.4\%) of the strains isolated from water exhibited a multidrug-resistance phenotype, and the prevalence 
TABLE 3 | Results of $\beta$-lactamase gene types, integrons and transconjugants of $\beta$-lactamase -producing Enterobacteriaceae from water of the Pearl River in Guangzhou.

\begin{tabular}{|c|c|c|c|c|c|c|}
\hline No. & Strains & Resources & Species & $\beta$-lactamase phenotypes & Integrons & Transconjugants $^{a}$ \\
\hline 1 & S1B-1 & Water & E. coli & CTX-M-65+SHV-1+TEM-1 & Intl & - \\
\hline 2 & S4-1 & Water & C. frediii & SHV-1 & Intl & + \\
\hline 3 & S23A-2 & Water & K. pneumoniae & TEM-1 & Intl & - \\
\hline 4 & S17-1 & Water & Providencia rettgeri & CTX-M-14+TEM-1 & $\ln t \mid$ & - \\
\hline 5 & S19-2 & Water & K. pneumoniae & CTX-M-14+SHV-1 & Intl & + \\
\hline 6 & S27-1 & Water & E. coli & CTX-M-55+SHV-1 & Intl & + \\
\hline 7 & S37-4 & Water & E. coli & SHV-1 & $\ln t \mid$ & - \\
\hline 8 & S38-2 & Water & C. freundii & TEM-1+ CMY-2 & $\ln t \mid$ & + \\
\hline 9 & S40-3 & Water & E. coli & CTX-M-15+SHV-1 & $\ln t \mid$ & - \\
\hline 10 & S41-1 & Water & E. coli & TEM-1+CMY-2 & Intl & - \\
\hline 11 & S16A-1 & Water & S. marcescens & $\mathrm{DHA}-1$ & Intl & - \\
\hline 12 & S18-2 & Water & E. coli & CMY-2 & Intl & - \\
\hline 13 & S29-1 & Water & E. cloacae & $\mathrm{DHA}-1$ & Intl & + \\
\hline 14 & S35-1 & Water & C. freundii & $\mathrm{DHA}-1$ & Intl & - \\
\hline 15 & S38-1 & Water & E. cloacae & DHA-1 & Intl & - \\
\hline 16 & S41-3 & Water & C. freundii & DHA-1 & Intl & - \\
\hline 17 & S42-4 & Water & E. cloacae & $\mathrm{DHA}-1$ & Intl & - \\
\hline
\end{tabular}

a, +, have been obtained transconjugants; -, have not been obtained transconjugants.

TABLE 4 | The occurrence of ESBL- and AmpC producing Enterobacteriaceae isolated from retail food and water of the Pearl River in Guangzhou.

\begin{tabular}{lccc}
\hline Product category & Total tests & ESBL No. (\%) & AmpC No. (\%) \\
\hline Water & 43 & $5(11.6)$ & $7(16.3)$ \\
Retail food & 88 & $3(3.4)$ & $12(13.6)$ \\
Total & 131 & $8(6.1)$ & $19(14.5)$ \\
\hline
\end{tabular}

was higher than that previously reported by others in studies of Pearl River (Tao et al., 2010), and was even higher than the common antibiotic resistance profiles of Enterobacteriaceae in aquatic environments (Zou et al., 2012; Maravic' et al., 2015). In particular, the highest resistance rates were observed against the penicillin antibiotics TE and FOX, which were higher than the common antibiotic resistance profiles of Enterobacteriaceae. Furthermore, the levels of resistance to C, CIP, LEV, and SXT were higher than those previously reported in aquatic environments (Tao et al., 2010). In addition, in the present study, a high percentage $(41.7 \%)$ of the strains isolated from retail food exhibited a multidrug-resistance phenotype, and the prevalence was higher than that previously reported by others in studies (Fernández-Fuentes et al., 2012; Campos et al., 2015). Notably, resistance to carbapenems has seldom been found, and these drugs therefore remain the first choice for treatment of serious infections for Enterobacteriaceae; however, the prevalence both in retail food and water was higher than that previously reported (Chen et al., 2012). This phenomenon might be explained by the abuse use of carbapenems antibiotics. Therefore, promotion of the rational use of antibiotics should be strengthened, especially the use of carbapenems, and governmental agencies should formulate policies to control the use of antibiotics to help reduce the emergence of resistant strains.

Relatively few publications have described the incidence of ESBL and AmpC producers in Enterobacteriaceae isolated from food, and those that exist have mainly focused on meat products or animals, without discrimination of which species were detected in which food types (Ojer-Usoz et al., 2013; AbdelMoein and Samir, 2014; Casella et al., 2015; Zurfluh et al., 2015). The present study revealed a prevalence of $3.4 \%$ of ESBLproducing Enterobacteriaceae in retail food, which is consistent with previously reported (van Hoek et al., 2015), but lower than detected in other studies (Geser et al., 2012; Ojer-Usoz et al., 2013; Said et al., 2015); while the prevalence of AmpC-producing Enterobacteriaceae is higher than previously reported (van Hoek et al., 2015). In general, a high incidence of ESBL and AmpC producers was detected in foods of animal origin (i.e., raw meat products and aquatic products), which was in agreement with the results of previous studies (Ojer-Usoz et al., 2013; Casella et al., 2015). However, the prevalence of ESBL- and AmpC-producing Enterobacteriaceae in frozen food was higher than that in raw meat products and aquatic products, indicating that frozen foods may be susceptible to cross-contamination in the production process. The present study revealed a prevalence of $11.6 \%$ and $16.3 \%$ of ESBL- and AmpC-producing Enterobacteriaceae in water samples, which is higher than previously reported (Maravic' et al., 2015). Notably, we found that the prevalence of AmpC- producing bacteria was higher in ESBL- producing bacteria than previously reported (Reich et al., 2013; van Hoek et al., 2015). This phenomenon might be explained by the variable use of antibiotics in different countries. 

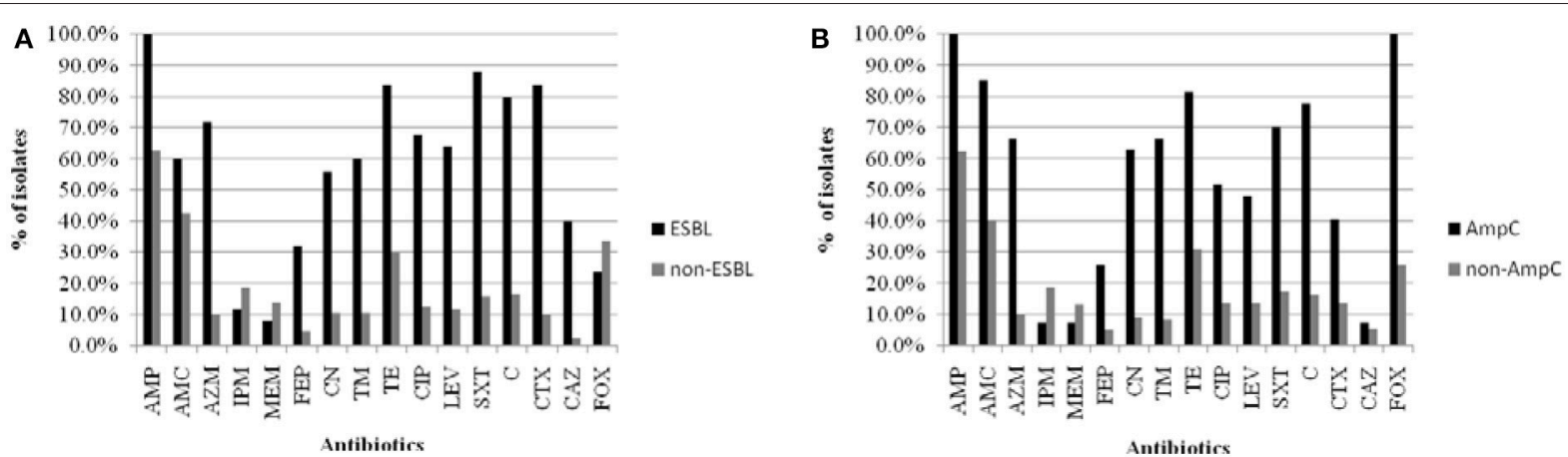

FIGURE 3 | The comparison of resistant rates between $\beta$-lactamase-producing positive strains and negative strains isolated from food and water of the Pearl River in Guangzhou. (A) ESBL-producing postive strains and negative strains. (B) AmpC-producing postive strains and negative strains. Abbreviations: AMP, ampicillin; AMC, amoxicillin/clavulanic acid; AZM, aztreonam; IPM, imipinem; MEM, meropenem; FEP, cefepime; CN, gentamicin; TM, tobramycin; TE, tetracycline; CIP, ciprofloxacin; LEV, levofloxacin; SXT, trimethoprim/sulfamethoxazole; C, chloramphenicol; CTX, cefotaxime; CAZ, ceftazidime; FOX, cefoxitin.

Throughout the study period, 10 genera of $\beta$-lactamaseproducing and ESBL-positive Enterobacteriaceae were observed in retail food and water samples. E. coli was the predominant ESBL producer both in retail food and water samples, consistent with the results of other studies (Yang et al., 2009; Lu et al., 2010; Mokracka et al., 2012; Korzeniewska and Harnisz, 2013). However, C. freundii and Morganella morganii, and E. cloacae was the most frequently isolated AmpC-producing species in retail food and water samples, respectively, which is in contrast with the predominance of $E$. coli and $K$. pneumoniae in clinical samples (Cejas et al., 2012), as well as the results of previous studies showing the dominance of Enterobacter spp. in other environments (Maravic' et al., 2015). The differences in the occurrence of ESBL- and AmpC-producing Enterobacteriaceae in retail food and water may also be associated with the source and quantity of strains, and the variable use of antimicrobial agents in different countries and geographical regions.

Many studies have found that the generation of ESBL and AmpC enzymes is the primary mechanism of antibiotic resistance in Enterobacteriaceae, which allows for the hydrolysis of cephalosporin antibiotics, except for fourth-generation cephalosporins such as FEP (Ben Sallem et al., 2014; Blaak et al., 2014; Durso and Cook, 2014). The present results showed a higher resistance rate in $\beta$-lactamase-producing positive strains than negative strains, and all AmpC-producing Enterobacteriaceae strains were resistant to FOX and AMC. Our data suggest that strains harboring plasmid-mediated AmpC $\beta$ lactamase have strong ability to hydrolyze FOX, and are usually not inhibited by the "classical" $\beta$-lactamase inhibitors such as clavulanic acid, which is consistent with a previous report (Jacoby et al., 2009; Pitout et al., 2010). In vitro susceptibility data suggest that the most reliable choice of therapy for infections of ESBL- and AmpC-producing Enterobacteriaceae is FEP and carbapenems (Paterson et al., 2001). In the present study, less than $25 \%$ of the $\beta$-lactamase-producing strains showed resistance against FEP and carbapenems, which contrasts with previous studies (Chen et al., 2012; Maravic' et al., 2015).
This phenomenon might be explained by the variable use of FEP and carbapenems in Guangzhou. The emergence of ESBLand AmpC-producing strains and the wide use of $\beta$-lactam antimicrobial agents has a direct causal relationship; therefore, measures for controlling the abuse of the third generation of cephalosporin should be formulated to reduce the emergence of more and more drug-resistant strains.

Because different countries and regions have different strategies and regulations for antibiotics use, the dominance of ESBL and AmpC enzyme types are varied along with geographical locations. TEM-, SHV-, and CTX-M-type $\beta$ lactamases are the major types in Europe and the Americas (Cant et al., 2008), SHV-type $\beta$-lactamase is dominant types in Japan (Yagi et al., 2000), and CTX-M -type $\beta$-lactamase is predominant types in China (Zhuo et al., 2013). In addition, CTX-M -type $\beta$-lactamase is the most prevalent type of ESBL in the world (BenAmi et al., 2009; Canton et al., 2012; Peirano et al., 2012). CMY-2 and DHA-1 are widely observed in clinical samples, and CMY-2 is currently the most prevalent type of plasmid-mediated AmpC worldwide (Whichard et al., 2005; Egorova et al., 2008). DHA1-producing strains have emerged as an important source of infections nationwide in China (Gupta et al., 2003). In our study, SHV- and TEM-type $\beta$-lactamases were identified as belonging to the genotypes SHV-1 and TEM-1, respectively. Unlike TEM-1 and SHV-1, which are broad-spectrum $\beta$-lactamases that confer resistance to penicillins and first-generation cephalosporins, but not to third- and fourth-generation cephalosporins (Dierikx et al., 2012), CTX-M is derived from the preferential activity for CTX over CAZ (Paterson and Bonomo, 2005; Canton et al., 2012); therefore, the fact that the rate of resistance to CAZ was below that to CTX may be due to the higher prevalence of strains carrying $b l a_{C T X-M}$. The CTX-M variants detected in our study (CTX-M-14, CTX-M-15, CTX-M-55, and CTXM-65) correspond to the most frequently observed CTX-M variants reported in previous studies (Ben Sallem et al., 2012; Reuland et al., 2014; Veldman et al., 2014). Furthermore, we found that DHA-1 was predominant among AmpC-producing Enterobacteriaceae isolates from both retail food and water 


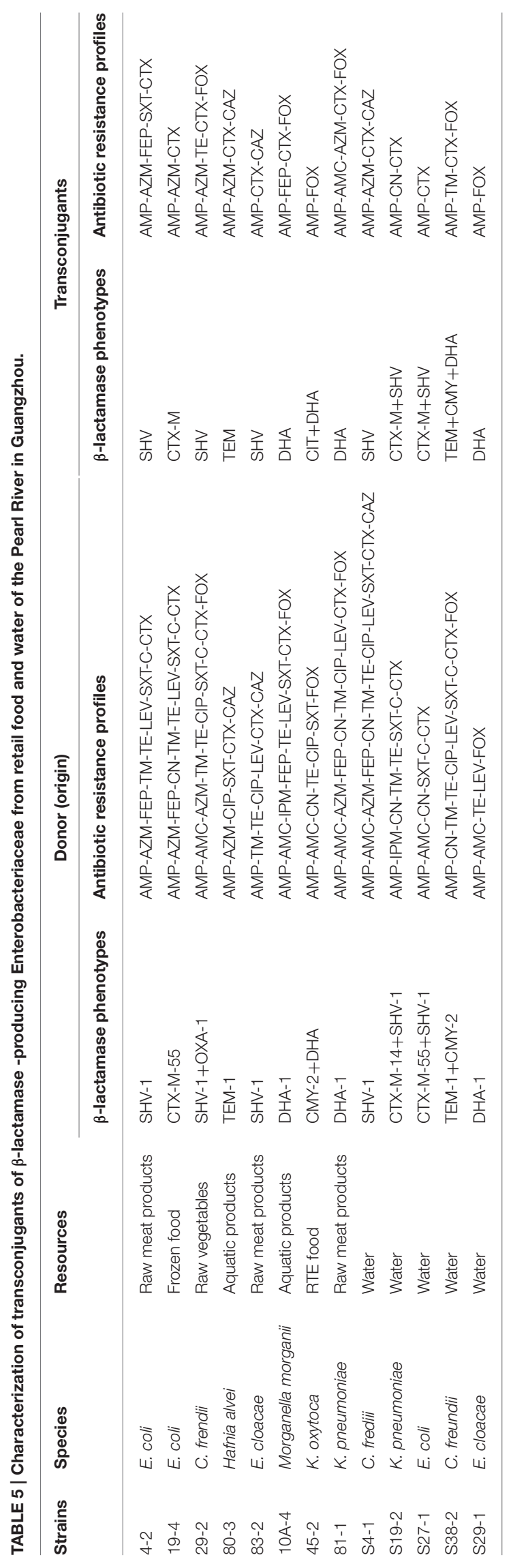

samples in Guangzhou, which is in agreement with the results of other studies (Gupta et al., 2003). All of the ESBL- and AmpCproducing Enterobacteriaceae detected in the present study showed a multi-resistance phenotype and harbored integrons, which is also consistent with previous reports (Schmiedel et al., 2014; Said et al., 2015). Except for one strain that simultaneously carried both the ESBL and AmpC enzymes, all isolates harbored either ESBL or AmpC alone, demonstrating that the generation of ESBL and plasmid-mediated AmpC $\beta$ lactamase is the primary mechanism of antibiotic resistance in Enterobacteriaceae isolated from retail food and water of Pearl River in Guangzhou. In the conjugation transfer experiments, 13 isolates were detected as transconjugants, which illustrated the overall high population of ESBL- and AmpC-producing Enterobacteriaceae in Guangzhou. These transconjugants could receive the $\beta$-lactamase genes conferring resistance to $\beta$-lactam antibiotics and some non- $\beta$-lactam antibiotics. These results indicated that these plasmids not only carry genes encoding ESBL or/and AmpC $\beta$-lactamases but can also spread horizontally among Enterobacteriaceae, which has likely contributed to the prevalence of resistance to antimicrobials for $\beta$-lactams and some non- $\beta$-lactams, leading to a high incidence of multidrug resistance.

\section{CONCLUSIONS}

We here report the results of the first investigation of the prevalence of ESBL- and AmpC-producing Enterobacteriaceae isolated from retail foods and water of Pearl River in Guangzhou. This work showed that retail foods (including raw meat products, aquatic products, mushrooms, raw vegetables, and frozen foods) and freshwater sources are important vehicles for the dissemination of ESBL- and AmpC-producing enterobacteria. Therefore, close surveillance of antimicrobial resistance in bacteria from food-producing and derived food products and freshwater should be established as a priority. In addition, strategies to control the use of antimicrobial agents in food and freshwater are urgently required to suppress the release of multiple drug-resistant bacteria harboring ESBL and plasmid-mediated cephalosporinase genes in these reservoirs.

\section{AUTHOR CONTRIBUTIONS}

QY contributed to designed the work that led to the submission, acquired data, and played an important role in interpreting the results; QW contributed to revised the manuscript and approved the final version; GY, $\mathrm{HW}$, and $\mathrm{JH}$ helped to acquired data; SZ, JZ, MC, LX, and JW helped perform the analysis with constructive discussions.

\section{FUNDING}

The authors would like to acknowledge the financial support of National Natural Science Foundation of 
China (31371780); Science and Technology Program of Guangdong Province (2014B050504007); Science and Technology Program of Guangzhou, China (201508020037); Key projects in the National Science \& Technology Pillar Program during the Twelve Five year Plan Period (2013BAD16B05).

\section{REFERENCES}

Abate, M., Wolde, T., and Alemu, A. N. (2016). Bacterial contaminations of raw cow's milk consumed at Jigjiga City of Somali Regional State, Eastern Ethiopia. Int. J. Food Contaminatior 3, 4. doi: 10.1186/S40550-0160027-5

Abdel-Moein, K. A., and Samir, A. (2014). Occurrence of extended spectrum $\beta$ lactamase-producing Enterobacteriaceae among pet dogs and cats: an emerging public health threat outside health care facilities. Am. J. Infect. Control 42, 796-798. doi: 10.1016/j.ajic.2014.03.020

Bain, R., Cronk, R., Hossain, R., Bonjour, S., Onda, K., Wright, J., et al. (2014). Global assessment of exposure to faecal contamination through drinking water based on a systematic review. Trop. Med. Int. Health 19, 917-927. doi: $10.1111 /$ tmi.12334

Ben Sallem, R., Ben, K., Rojo-Bezares, B., and Torres, C. (2014). IncI1 plasmids carrying blaCTX-M-1 or blaCMY-2 genes in Escherichia coli from healthy humans and animals in Tunisia. Microb. Drug Resist. 20, 495-500. doi: $10.1089 / \mathrm{mdr} .2013 .0224$

Ben Sallem, R., Ben, S. K., Sáenz, Y., Rojo-Bezares, B., Estepa, V., Jouini, A., et al. (2012). Prevalence and characterization of extended-spectrum betalactamase (ESBL)- and CMY-2-producing Escherichia coli isolates from healthy food-producing animals in Tunisia. Foodborne Pathog. Dis. 9, 1137-1142. doi: $10.1089 /$ fpd.2012.1267

Ben-Ami, R., Rodríguez-Baño, J., Arslan, H., Pitout, J. D. D., Quentin, C., Calbo, E. S., et al. (2009). A multinationalsurvey of risk factors for infection with extended-spectrum beta-lactamase-producing Enterobacteriaceae in nonhospitalized patients. Clin. Infect. Dis. 49, 682-690. doi: 10.1086/ 604713

Blaak, H., van Hoek, A. H., Veenman, C., Docters van Leeuwen, A. E., Lynch, G., van Overbeek, W. M., et al. (2014). Extended spectrum ß-lactamaseand constitutively AmpC-producing Enterobacteriaceae on fresh produce and in the agricultural environment. Int. J. Food Microbiol. 168-169, 8-16. doi: 10.1016/j.ijfoodmicro.2013.10.006

Bush, K., and Jacoby, G. A. (2010). Updated functional classification of beta-lactamases. Antimicrob. Agents Chemother. 54, 969-976. doi: 10.1128/AAC.01009-09

Calbo, E., Freixas, N., Xercavins, M., Riera, M., Nicolás, C., Monistrol, O., et al. (2011). Foodborne nosocomial outbreak of SHV1 and CTX-M-15producing Klebsiella pneumoniae: epidemiology and control. Clin. Infect. Dis. 52, 743-749. doi: 10.1093/cid/ciq238

Campos, J., Gil, J., Mourão, J., Peixe, L., and Antunes, P. (2015). Ready-toeat street-vended food as a potential vehicle of bacterial pathogens and antimicrobial resistance: an exploratory study in Porto region, Portugal. Int. J. Food Microbiol. 206, 1-6. doi: 10.1016/j.ijfoodmicro.2015.04.016

Cant, O. N. R., Novais, A., Valverde, A., Machado, E., Peixe, L., Baquero, F., et al. (2008). Prevalence and spread of extended-spectrum beta-lactainaseproducing Enterobacteriaceae in Europe [J]. Clin. Microbiol. Infect. 14, 144-153. doi: 10.1111/j.1469-0691.2007.01850.x

Cantón, R., González-Alba, J. M., and Galán, J. C. (2012). CTX-M enzymes: origin and diffusion. Front. Microbiol. 3:110. doi: 10.3389/fmicb.2012.00110

Casella, T., Rodríguez, M. M., Takahashi, J. T., Ghiglione, B., Dropa, M., Assunção, E. et al. (2015). Detection of blaCTX-M-type genes in complex class 1 integrons carried by Enterobacteriaceae isolated from retail chicken meat in Brazil. Int. J. Food Microbiol. 197, 88-91. doi: 10.1016/j.ijfoodmicro.2014.12.001

Cejas, D., Canigia, L. F., Quinteros, M. G., and Radice, M. (2012). PlasmidEncoded AmpC (pAmpC) in Enterobacteriaceae: epidemiology of microorganisms and resistance markers. Rev. Argent. Microbiol. 44, $182-186$

\section{SUPPLEMENTARY MATERIAL}

The Supplementary Material for this article can be found online at: http://journal.frontiersin.org/article/10.3389/fmicb. 2017.00096/full\#supplementary-material

Table S1 | Sequences of primers used in paper.

Chen, J., Jin, M., Qiu, Z. G., Guo, C., Chen, Z. L., Shen, Z. Q., et al. (2012). A survey of drug resistance bla genes originating from synthetic plasmid vectors in six chinese rivers. Environ. Sci. Technol. 46, 13448-13454. doi: 10.1021/es302760s Clinical and Laboratory Standards Institute (2011). Performance Standards for Antimicrobial Susceptibility Testing: Twenty-first Informational Supplement 2012, Vol. 31. Wayne, IL: CLSI.

Coudron, P. E., Moland, E. S., and Thomson, K. S. (2000). Occurrence and detection of AmpC beta-lactamases among Escherichia coli, Klebsiella pneumoniae, and Proteus mirabilis isolates at a veterans medical center. J. Clin. Microbiol. 38, 1791-1796.

Dierikx, C. M., Duijkeren, E., Schoormans, A. H. W., Essen-Zandbergen, A., Veldman, K., Kant, A., et al. (2012). Occurrence and characteristics of extended-spectrum- $\beta$-lactamase and $\mathrm{AmpC}$-producing clinical isolates derived from companion animals and horses. J. Antimicrob. Chemother. 67, 1368-1374. doi: $10.1093 / \mathrm{jac} / \mathrm{dks} 049$

Durso, L. M., and Cook, K. L. (2014). Impacts of antibiotic use in agriculture: what are the benefits and risks [J]? Curr. Opin. Microbiol. 19, 37-44. doi: 10.1016/j.mib.2014.05.019

Egorova, S., Timinouni, M., Demartin, M., Sophie, A. G., Jean, M. W., Sangal, V., et al. (2008). Ceftriaxone-resistant Salmonella enterica serotype Newport, France. Emerg. Infect. Dis. 14, 954-957. doi: 10.3201/eid1406.071168

Fernández-Fuentes, M. A., Ortega, E., Abriouel, H., and Gálvez, A. (2012). Isolation and identification of bacteria from organic foods: sensitivity to biocides and antibiotics. Food Control 26, 73-78. doi: 10.1016/j.foodcont.2012.01.017

Geser, N., Stephan, R., and Hächler, H. (2012). Occurrence and characteristics of extended-spectrum beta-lactamase (ESBL) producing Enterobacteriaceae in food producing animals, minced meat and raw milk. BMC Vet. Res. 8:21. doi: 10.1186/1746-6148-8-21

Gharout-Sait, A., Touati, A., Guillard, T., Brasme, L., and de Champs, C. (2015). Molecular characterization and epidemiology of cefoxitin resistance among Enterobacteriaceae lacking inducible chromosomal ampC genes from hospitalized and non-hospitalized patients in Algeria: description of new sequence type in Klebsiella pneumoniae isolates. Braz. J. Infect Dis. 19, 187-195. doi: 10.1016/j.bjid.2014.12.001

Gupta, A., Fontana, J., and Crowe, C. (2003). Emergence of multidrug-resistant Salmonella enterica serotype Newport infections resistant to expandedspectrum cephalosporins in the United States. J. Infect. Dis. 188, 1707-1716. doi: $10.1086 / 379668$

Jacoby, G. A. (2009). AmpC $\beta$-lactamases. Clin. Microbiol. Rev. 22, 161-182. doi: 10.1128/CMR.00036-08

Jarzab, A., Gorska-Fraczek, S., Rybka, J., and Witkowaka, D. (2011). Enterobacteriaceae infection-diagnosis, antibitioc resistance and prevention. Postepy Hig. Med. Dosw. 65, 55-72. doi: 10.5604/17322693.933273

Kallova, J., Macickova, T., and Majtanova, A. (1995). Transferable amikacin resistance in gram-negative bacterial isolates. Chemotherapy 41, 187-192. doi: $10.1159 / 000239342$

Kanamoria, H., Navarro, R. B., and Yanoc, H. (2011). Molecular characteristics of extended-spectrum-lactamases in clinical isolates of Enterobacteriaceae from the Philippines. Acta Trop. 120, 140-145. doi: 10.1016/j.actatropica.2011.07.007

Kant, A., and Mevius, D. (2013). Increasing prevalence and diversity of ESBL/AmpC-type beta-lactamase genes in Escherichia coli isolated from veal calves from 1997 to 2010. J. Antimicrob. Chemother. 68, 1970-1973. doi: $10.1093 /$ jac/dkt132

Knapp, C. W., McCluskey, S. M., Singh, B. K., Campbell, C. D., Hudson, G., and Graham, D. W. (2011). Antibiotic resistance gene abundances correlate with metal and geochemical conditions in archived Scottish soils. PLoS ONE 6:e27300. doi: 10.1371/journal.pone.0027300 
Korzeniewska, E., and Harnisz, M. (2013). Beta-lactamase-producing Enterobacteriaceae in hospital effluents. J. Environ. Manage. 123, 1-7. doi: 10.1016/j.jenvman.2013.03.024

Lane, D. J. (1991). "16S/23S rRNA sequencing," in Nucleic Acid Techniques in Bacterial Systematics, eds E. Stackebrandt and M. Goodfellow (Chichester: Wiley), 115-175.

Lee, J. H., Bae, I. K., and Lee, S. H. (2012). New definitions of extended-spectrum beta-lactamase conferring worldwide emerging antibiotic resistance. Med. Res. Rev. 32, 216-232. doi: 10.1002/med.20210

Leistner, R., Schroder, C., Geffers, A., Breier, C., Gastmeier, P., and Behnke, M. (2015). Regional distribution of nonsocomial infections due too ESBL-positive enterobacteriaeae in Germany: data from the German Natinal reference center for the surveillance of Nosnocomial infections (KISS). Clin. Microbiol. Infect. 21, 255e1-255e5. doi: 10.1016/j.cmi.2014.07.015

Leverstein-van Hall, M. A., Dierikx, C. M., Cohen, S. J., Voets, G. M., Munckhof, M. P., Essen-Zandbergen, A., et al. (2011). Dutch patients, retail chicken meat and poultry share the same ESBL genes, plasmids and strains. Clin. Microbiol. Infect. 17, 873-880. doi: 10.1111/j.1469-0691.2011.03497.x

Li, Y. W., Wu, X. L., Mo, C. H., Tai, Y. P., Huang, X. P., and Xiang, L. (2011). Investigation of sulfonamide, tetracycline, and quinolone antibiotics in vegetable farmland soil in the Pearl River Delta Area, Southern China. J. Agric. Food Chem. 59, 7268-7276. doi: 10.1021/jf1047578

Livermore, D. M. (2008). Defining an extended-spectrum beta-lactamase. Clin. Microbiol. Infect. 14, 3-10. doi: 10.1111/j.1469-0691.2007.01857.x

Lu, S. Y., Zhang, Y. L., Geng, S. N., Li, T. Y., Ye, Z. M., Zhang, D. S., et al. (2010). High diversity of extended-spectrum beta-lactamase-producing bacteria in an urban river sediment habitat. Appl. Environ. Microbiol. 76, 5972-5976. doi: 10.1128/AEM.00711-10

Machado, E., Coque, T. M., Canton, R., Sousa, J. C., Silva, D., Ramos, M., et al. (2009). Leakage into Portuguese aquatic environments of extended-spectrumb-lactamase-producing Enterobacteriaceae. J. Antimicrob.Chemother. 63, 616-618. doi: 10.1093/jac/dkn510

Maravic', A., Skoc'ibušic', M., Cvjetan, S., Šamanic', I., Fredotovic', Z., and Puizina, J. (2015). Prevalence and diversity of extended-spectrum- $\beta$-lactamase-producing Enterobacteriaceae from marine beach waters. Mar. Pollut. Bull. 90, 60-67. doi: 10.1016/j.marpolbul.2014.11.021

Mokracka, J., Koczura, R., and Kaznowski, A. (2012). Multiresistant Enterobacteriaceae with class 1 and class 2 integrons in a municipal wastewater treatment plant. Water Res. 46, 3353-3363. doi: 10.1016/j.watres.2012.03.037

Nielsen, L., Kjerulf, A., and Arpi, M. (2015). Increasing incidence of Extended-spectrum-beta-lactamase-producing Enterobacteriaceae (ESBL) and the relation to consumption of broad-spectrum antimicrobial agnets 2003-2011 in a Large area of Copenhagen, Denmmark. Open J. Med. Microbiol. 5, 28-42. doi: 10.4236/ojmm.2015.51005

Nordmann, P., Naas, T., and Poirel, L. (2011). Global spread of carbapenemaseproducing enterobacteriaceae. Emerg. Infect. Dis. 17, 1791-1798. doi: 10.3201/eid1710.110655

Ojer-Usoz, E., González, D., Vitas, A. I., Leiva, J., García-Jalón, I., Febles-Casquero, A., et al. (2013). Prevalence of extended-spectrum $\beta$-lactamase-producing Enterobacteriaceae in meat products sold in Navarra, Spain. Meat Sci. 93, 316-321. doi: 10.1016/j.meatsci.2012.09.009

Overdevest, I., Willemsen, I., Rijnsburger, M., Eustace, A., Xu, L., Hawkey, P., et al. (2011). Extended-spectrum $\beta$-lactamase genes of Escherichia coli in chicken meat and humans, the Netherlands. Emerg. Infect. Dis. 17, 1216-1222. doi: 10.3201/eid1707.110209

Paterson, D., Ko, W. C., and Gottberg, A. (2001). Outcome of cephalosporin treatment for serious infections due to apparently susceptible organisms producing extended-spectrum $\beta$-lactamases: implications for the clinical microbiology laboratory. J. Clin. Microbiol. 39, 2206-2212. doi: 10.1128/JCM.39.6.2206-2212.2001

Paterson, D. L., and Bonomo, R. A. (2005). Extended-spectrum $\beta$ lactamases: a clinical update. Clin. Microbiol. Rev. 18, 657-686. doi: 10.1128/CMR.18.4.657-686.2005

Peirano, G., Sang, J. H., Pitondo-Silva, A., Laupland, K. B., and Pitout, J. D. (2012). Molecular epidemiology of extended-spectrum- $\beta$-lactamase-producing Klebsiella pneumoniae over a 10 year period in Calgary, Canada. J. Antimicrob. Chemother. 67, 1114-1120. doi: 10.1093/jac/dks026
Pérez-Pérez, F. J., and Hanson, N. D. (2002). Detection of plasmidmediated AmpC b-lactamase genes in clinical isolates by using multiplex PCR. J. Clin. Microbiol. 40, 2153-2162. doi: 10.1128/jcm.40.6.2153-2162.2002

Pfeiier, Y., Cullik, A., and Witte, W. (2010). Resistance to cephalosporins and carbapenems in Gram-negative bacterial pathogens. Int. J. Med. Microbiol. 300, 371-379. doi: 10.1016/j.ijmm.2010.04.005

Philippon, A., Arlet, G., and Jacoby, G. A. (2002). Plasmid-determined AmpC-typeß-lactamases. Antimicrob. Agents Chemother. 46, 1-11. doi: 10.1128/AAC.46.1.1-11.2002

Pitout, J. D. (2012). Extraintestinal pathogenic Escherichia coli: an update on antimicrobial resistance, laboratory diagnosis and treatment. Expert Rev. Anti Infect. Ther. 10, 1165-1176. doi: 10.1586/eri.12.110

Pitout, J. D., Le, P. G., Moore, K. L., Church, D. L., and Gregson, D. B. (2010). Detection of AmpC $\beta$-lactamases in Escherichia coli, Klebsiella spp., Salmonella spp. and Proteus mirabilis in a regional clinical microbiology laboratory. Clin. Microbiol. Infect. 16, 165-170. doi: 10.1111/j.1469-0691.2009.02756.x

Reich, F., Atanassova, V., and Klein, G. (2013). Extended-Spectrum ß-Lactamaseand AmpC-Producing Enterobacteria in Healthy Broiler Chickens, Germany. Emerg. Infect. Dis. 19, 1253-1259. doi: 10.3201/eid1908.120879

Reuland, E. A., AlNaiemi, N., Raadsen, S. A., Savelkoul, P. H. M., Kluytmans, J. A. J. W., and Vandenbroucke-Grauls, C. M. J. E. (2014). Prevalence of ESBLproducing Enterobacteriaceae in raw vegetables. Eur. J. Clin. Microbiol. Infect. Dis. 33, 1843-1846. doi: 10.1007/s10096-014-2142-7

Sáenz, Y., Briñas, L., Domínguez, E., Ruiz, J., Zarazaga, M., Vila, J., et al. (2004). Mechanisms of resistance in multiple-antibiotic-resistant Escherichia coli strains of human, animal, and food origins. Antimicrob. Agents Chemother. 48, 3996-4001. doi: 10.1128/AAC.48.10.3996-4001.2004

Said, L. B., Jouini, A., Klibi, N., Dziri, R., Alonso, C. A., Boudabous, A., et al. (2015). Detection of extended-spectrum beta-lactamase (ESBL)producing Enterobacteriaceae in vegetables, soil and water of the farm environment in Tunisia. Int. J. Food Microbiol. 203, 86-92. doi: 10.1016/j.ijfoodmicro.2015.02.023

Schmiedel, J., Falgenhauer, L., Domann, E., Bauerfeind, R., Prenger-Berninghoff, E., Imirzalioglu, C., et al. (2014). Multiresistant extended-spectrum $\beta$ lactamase-producing Enterobacteriaceae from humans, companion animals and horses in central Hesse, Germany. BMC Microbiol. 14:187. doi: 10.1186/1471-2180-14-187

Singhal, S., Mathur, T., Khan, S., and Rattan, A. (2005). Evaluation of methods for AmpC $\beta$-lactamase in Gram negative climcal isolates from tertiary care hospitals. Indian J. Med. Microbiol. 23, 120-124. doi: 10.4103/0255-0857.16053

Soha, A. E., and Lamiaa, A. A. (2015). Occurrence and detection of AmpC $\beta$-lactamases among Enterobacteriaceae isolates from patients at Ain Shams University Hospital. Egypt. J. Med. Hum. Genet. 16, 239-244. doi: 10.1016/j.ejmhg.2015.03.001

Stalder, G. L., Loncaric, I., and Walzer, C. (2014). Diversity of enterobacteria including $\beta$-lactamase producing isolates associated with the Spanish slug (Arion vulgaris). Sci. Total Environ. 479-480, 11-16. doi: 10.1016/j.scitotenv.2014.01.103

Tacão, M., Correia, A., and Henriques, I. (2012). Resistance to broadspectrum antibiotics in aquatic systems: anthropogenic activities modulate the dissemination of blaCTX-M-like genes. Appl. Environ. Microbiol. 78, 4134-4140, doi: 10.1128/AEM.00359-12

Tao, R., Ying, G. G., Su, H. C., Zhou, H. W., and Sidhu, J. P. S. (2010). Detection of antibiotic resistance and tetracycline resistance genes in Enterobacteriaceae isolated from the Pearl rivers in South China. Environ. Pollut. 158, 2101-2109. doi: 10.1016/j.envpol.2010.03.004

Thaker, H. C., Brahmbhatt, M. N., and Nayak, J. B. (2012). Study on occurrence and antibiogram pattern of $E$. coli from raw milk samples in Anand, Gujarat, India. Vet. World 5, 556-559.

Thevenon, F., Adatte, T., Wildi, W., and Poté, J. (2012). Antibiotic resistant bacteria/genes dissemination in lacustrine sediments highly increased following cultural eutrophication of Lake Geneva (Switzerland). Chemosphere 86, 468-476. doi: 10.1016/j.chemosphere.2011.09.048

van Hoek, A. H. A. M., Veenman, C., van Overbeek, W. M., Lynch, G., de Roda Husman, A. M., and Blaak, H. (2015). Prevalence and characterization of ESBL- and AmpC-producing Enterobacteriaceae on retail vegetables. Int. J. Food Microbiol. 204, 1-8. doi: 10.1016/j.ijfoodmicro.2015.03.014 
Veldman, K., Kant, A., Dierikx, C., van Essen-Zandbergen, A., Wit, B., and Mevius, D. (2014). Enterobacteriaceae resistant to third-generation cephalosporins and quinolones in fresh culinary herbs imported from Southeast Asia. Int. J. Food Microbiol. 177, 72-77. doi: 10.1016/j.ijfoodmicro.2014. 02.014

Whichard, J. M., Joyce, K., Fey, P. D., and Timothy, J. B. (2005). $\beta$-Lactam resistance and Enterobacteriaceae, United States. Emerg. Infect. Dis. 11, 1464-1466. doi: 10.3201/eid1109.050182

World Health Organization (2012). The Evolving Threat of Antimicrobial Resistance - Options for Action. Geneva: WHO. Available online at: http://apps. who.int/iris/bitstream/10665/44812/1/9789241503181_eng.pdf

Yagi, T., Kurokawa, H., and Shibata, N. (2000). A preliminary survey of extended-spectrum beta-lactaxnases (ESBLs) in clinical isolates of Klebsiella pneumoniae and Escherichia coli in Japan. FEMS Microbiol. Lett. 184, 53-56.

Yang, C. M., Lin, M. F., Liao, P. C., Yeh, H. W., Chang, B. V., Tang, T. K. et al. (2009). Comparison of antimicrobial resistance patterns between clinical and sewage isolates in a regional hospital in Taiwan. Lett. Appl. Microbiol. 48, 560-565. doi: 10.1111/j.1472-765X.2009.02572.x

Yang, J. F., Ying, G. G., Zhao, J. L., Tao, R., Su, H. C., and Chen, F. (2010). Simultaneous determination of four classes of antibiotics in sediments of the Pearl Rivers using RRLC-MS/MS. Sci. Total Environ. 408, 3424-3432. doi: $10.1016 /$ j.scitotenv.2010.03.049

Yang, J. F., Ying, G. G., Zhao, J. L., Tao, R., Su, H. C., and Liu, Y. S. (2011). Spatial and seasonal distribution of selected antibiotics in surface waters of the Pearl Rivers, China. J. Environ. Sci. Health B 46, 272-280. doi: 10.1080/03601234.2011.540540

Yuan, L., Liu, J. H., Hu, G. Z., Pan, Y., S., Mo, J., and Wei, Y. J. (2009). Molecular characterization of extended-spectrum-beta-lactamase-producing $E$. coli isolates from chickens in Henan Province, China. J. Med. Microbiol. 58, 1449-1453. doi: 10.1099/jmm.0.012229-0

Zhuo, C., Li, X. Q., Zong, Z. Y., and Zhong, N. S. (2013). Epidemic plasmid carrying blaCTX-M-15 in Klebsiella penumoniae in China. PLoS ONE 8:e52222. doi: 10.1371/journal.pone.0052222

Zou, L. K., Li, L. W., Pan, X., Tian, G. B., Luo, Y., Wu, Q., et al. (2012). Molecular characterization of $\beta$-lactam-resistant Escherichia coli isolated from Fu River, China. World J. Microbiol. Biotechnol. 28, 1891-1899. doi: 10.1007/s11274-011-0987-9

Zurfluh, K., Glier, M., Hächler, H., and Stephan, R. (2015). Replicon typing of plasmids carrying blaCTX-M-15 among Enterobacteriaceae isolated at the environment, livestock and human interface. Sci. Total Environ. 521-522, 75-78. doi: 10.1016/j.scitotenv.2015.03.079

Conflict of Interest Statement: The authors declare that the research was conducted in the absence of any commercial or financial relationships that could be construed as a potential conflict of interest.

The reviewer BJ and handling Editor declared their shared affiliation and the handling Editor states that the process nevertheless met the standards of a fair and objective review.

Copyright $\odot 2017$ Ye, Wu, Zhang, Zhang, Yang, Wang, Huang, Chen, Xue and Wang. This is an open-access article distributed under the terms of the Creative Commons Attribution License (CC BY). The use, distribution or reproduction in other forums is permitted, provided the original author(s) or licensor are credited and that the original publication in this journal is cited, in accordance with accepted academic practice. No use, distribution or reproduction is permitted which does not comply with these terms. 